\title{
PENGEMBANGAN STRATEGI PEMESINAN BENTUK RONGGA SEGITIGA UNTUK MENGURANGI WAKTU PEMESINAN
}

\author{
Mochammad Chaeron \\ Fakultas Teknik Industri, Jurusan Teknik Industri, \\ Universitas Pembangunan Nasional "Veteran" Yogyakarta \\ Jalan Babarsari No.2 Tambakbayan Yogyakarta 55281 \\ Email:m.chaeron@upnyk.ac.id
}

\begin{abstract}
ABSTRAK
Terdapat dua strategi untuk pemesinan bentuk rongga segitiga yaitu: direction parallel dan contour parallel. Kedua strategi tersebut masing-masing mempunyai kekurangan. Pada strategi direction parallel, untuk menyelesaikan pemesinan, harus ditambahkan lintasan pahat mengelilingi batas untuk menghilangkan scallop. Sedangkan pada strategi contour parallel, pemesinan harus dilakukan secara overlap untuk menghindari timbulnya daerah sisa pemesinan di tengah area bentuk rongga. Kedua hal tersebut menyebabkan terjadinya proses pemesinan berulang. Pengembangan terhadap strategi contour parallel dan direction parallel dilakukan untuk mengurangi sebanyak mungkin terjadinya proses pemesinan berulang itu. Penambahan ataupun penggantian lintasan pahat menjadi pilihan utama dalam pengembangan startegi ini.Pada akhirnya strategi hasil pengembangan berhasil memberikan lintasan pahat yang lebih pendek, yang berarti dengan menggunakan strategi hasil pengembangan, proses pemesinan bentuk rongga dapat dilakukan lebih cepat.
\end{abstract}

Kata kunci: bentuk rongga segitiga, strategi pemesinan, scallop, overlap

\begin{abstract}
There are two machining strategies exist for triangular pocket machining: direction parallel and contour parallel. Both of those strategies have a weakness. On direction parallel strategy, to finish the machining, we must add a tool path around the boundary to remove scallop. Whereas on contour parallel strategy, we must do machining with overlap to avoid unmachined area remain. Both of those can cause the repeated machining process. The development we've done, toward contour parallel and direction parallel strategy, have aim to reduce as much as appearance of the repeated machining process. We must add or change a tool path in develop this strategy.At last, the development strategy can give shorter toll path successfully. Its mean, with the development strategy, we can do triangular pocket machining faster.
\end{abstract}

Keywords: triangularpocket, machining strategy, scallop, overlap 


\section{PENDAHULUAN}

Operasi yang paling banyak dijumpai dalam pemesinan part-part logam adalah operasi pemesinan bentuk rongga (pocket), yaitu membuang semua material yang terdapat di dalam suatu batas (boundary) tertutup pada permukaan datar benda kerja sampai ke kedalaman tertentu (Kramer, 1992 dan Arya, et al., 2001). Bentuk rongga merupakan fitur khusus yang banyak dijumpai pada proses pemesinan di perusahaan pembuat mould dan dies. Daya saing perusahaan pembuat mould dan dies sangat ditentukan oleh kemampuan dalam memenuhi waktu penyelesaian pesanan. Karena itulah usaha-usaha untuk memperpendek waktu pemesinan selalu menjadi perhatian utama. Waktu penyelesaian pesanan mempunyai hubungan erat dengan perencanaan proses pemesinan. Waktu yang dibutuhkan untuk menyelesaikan pemesinan suatu fitur tergantung pada banyak faktor, di antaranya adalah karakteristik mesin, strategi pemesinan, ukuran dan jenis pahat yang dipilih, geometri fitur dan spesifikasi toleransi serta parameter pemesinan.

Faktor terpenting dalam pemesinan bentuk rongga adalah ukuran pahat karena semua faktor yang lain tergantung pada ukuran pahat (Kyoung, et al., 1997). Di sisi lain, penentuan ukuran pahat untuk pemesinan bentuk rongga seringkali bukanlah masalah yang mudah karena beberapa alasan (Veeramani dan Gau, 1997). Pertama, ada banyak kandidat pahat yang dapat dipakai untuk melakukan pemesinan. Kedua, isu-isu pemotongan berlebih (gauging) dan toleransi perlu diperhatikan selama penentuan ukuran pahat. Ketiga, prosedur penentuan ukuran pahat harus memperhatikan ukuran-ukuran yang tersedia dalam persediaan pahat.

Tugas perencana proses selanjutnya, setelah ukuran pahat diperoleh, adalah membangkitkan lintasan pahat. Ada dua strategi pemesinan yang banyak dipakai di dalam pembangkitan lintasan pahat untuk pemesinan bentuk rongga, yaitu contour parallel dan direction parallel (Arkin et al., 2000). Kedua strategi tersebut, direction parallel dan contour parallel, masing-masing mempunyai kelebihan dan kekurangan. Strategi direction parallel memungkinkan lintasan pahat tanpa overlap tapi menyisakan scallop di sepanjang sisi bentuk rongga (Veeramani dan Gau, 1997). Sedangkan strategi contour parallel memungkinkan lintasan pahat yang bebas scallop di sepanjang sisi bentuk rongga tapi membutuhkan overlap antar lintasan untuk menghindari daerah sisa di tengah-tengah daerah bentuk rongga (Kyoung, et al., 1997).

Strategi pemesinan yang berbeda akan memberikan panjang lintasan pahat yang berbeda pula. Sejak panjang lintasan pahat berbanding lurus dengan waktu pemesinan dan kebanyakan fungsi tujuan dalam optimasi proses pemesinan adalah minimasi waktu pemesinan, maka perencana proses harus membangkitkan lintasan pahat sedemikian sehingga panjang lintasan pahat seminimal mungkin. Hal tersebut dapat dicapai jika lintasan pahat mampu mengkover keseluruhan daerah bentuk rongga (tanpa daerah sisa) dengan overlap antar lintasan pahat seminimal mungkin.

\section{METODE PENELITIAN}

Materi utama yang menjadi dasar penelitian ini merupakan hasil studi literatur terhadap karya-karya ilmiah, hasil penelitian para pakar yang telah dimuat dalam buku maupun jurnal. Metode penelitian yang digunakan adalah metode teoritis, pengembangan strategi pemesinan dan studi kasus melalui contoh numeris.

Sesuai dengan asas metode teoritis, penelitian dilakukan dengan bersandar pada hasil studi literatur terhadap karya-karya ilmiah yang telah dihimpun, yang berkaitan dengan proses pemesinan bentuk rongga (pocket). Untuk mencapai tujuan penelitian, diperlukan pemahaman mengenai karakteristik pemesinan menggunakan mesin CNC milling, strategistrategi pemesinan yang ada untuk pemesinan bentuk rongga, metode-metode pembangkitan lintasan pahat dan asas-asas trigonometri segitiga untuk pemodelan lintasan pahat. Untuk pengembangan strategi, penelitian dilakukan dalam tiga tahap, yaitu:

\section{Tahap pengumpulan data.}

Tahap ini dilakukan untuk mendapatkan data panjang lintasan pahat dari strategipemesinan bentuk rongga yang eksis saat ini. Data tersebut diperoleh dengan cara memodelkan lintasan pahat secara grafis memakai perangkat lunak AutoCAD. 


\section{Tahap pengembangan strategi.}

Tahap ini dilakukan berbasis strategi direction parallel sedemikian sehingga memperpendek lintasan pahat yang digunakan untuk membuangscallop (daerah sisa). Selanjutnya lintasan pahat dari strategi pemesinan hasil pengembangan dimodelkan secara grafis kemudian secara matematis.

\section{Tahap Analisis.}

Pada tahap ini dilakukan analisis atau interpretasi berdasarkan hasil yang diperoleh pada tahap pengolahan data dan tahap pengembangan strategi melalui perbandingan aspek panjang lintasan pahat.

\section{Pengembangan Strategi Berbasis Strategi Direction Parallel}

Berbasis strategi direction parallel, dilakukan pengembangan metode pemotongan scallop sedemikian sehingga mampu mengurangi panjang lintasan pahat pada pemesinan bentuk rongga segitiga. Langkah-langkah penyusunan strategi direction paralleladalah sebagai berikut:pertama, melakukan offset ke dalam sejauh setengah diameter pahat $(r)$ dengan menggunakan pahat berdiameter 2r. Hasil offset adalah segitiga ABG (Gambar 1), kedua, tarik garis-garis yang sejajar dengan sisi terpanjang segitiga. Karena pemesinannya dapat dilakukan tanpa overlap maka jarak antar garis sejajar tersebut sama dengan diameter pahat $(2 r)$.

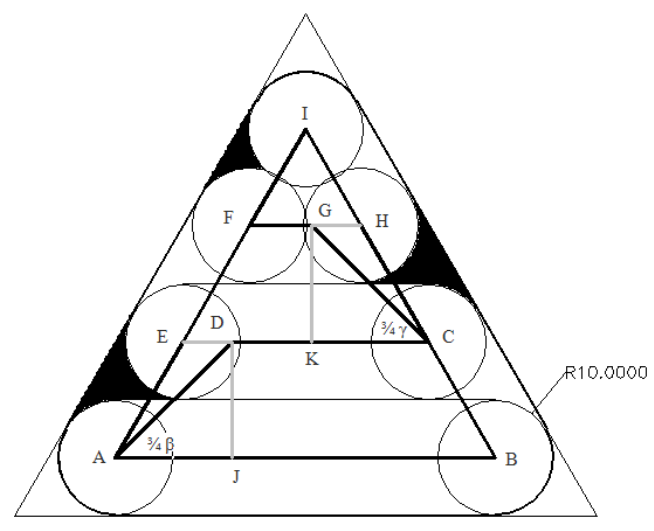

Gambar 1 Strategi pemesinan direction parallel

Dari Gambar 1, strategi direction parallel memiliki 3 bagian utama yaitu:

- Bagian mendatar (AB, $\mathrm{CD}$ dan seterusnya)

- Bagian menaik (BC, AF,dan seterusnya)

- Bagian untuk menghilangkan scallop di sepanjang batas bentuk rongga

\section{$\underline{\text { Panjang bagian mendatar: }}$}

$$
\begin{aligned}
& \overline{A B}=a-r \cdot \operatorname{Cot}\left(\frac{\beta}{2}\right)-r \cdot \operatorname{Cot}\left(\frac{\gamma}{2}\right)=a-r \cdot\left(\operatorname{Cot}\left(\frac{\beta}{2}\right)+\operatorname{Cot}\left(\frac{\gamma}{2}\right)\right) \\
& \overline{C E}=\overline{A B}-(2 \cdot r-\rho) \cdot(\operatorname{Cot}(\beta)+\operatorname{Cot}(\gamma)) \\
& \overline{C E}=a-r \cdot(\operatorname{Cot}(\beta / 2)+\operatorname{Cot}(\gamma / 2))-(2 \cdot r-\rho) \cdot(\operatorname{Cot}(\beta)+\operatorname{Cot}(\gamma))
\end{aligned}
$$

Banyaknya bagian mendatar (garis sejajar $\mathrm{AB})=i$, dapat dihitung sebagai berikut:

$$
i=\left[\frac{\overline{I L}}{(2 \cdot r-\rho)}\right]
$$


dan karena

$$
\overline{I L}=\overline{A I} \cdot \operatorname{Sin}(\beta)=(c-r \cdot \operatorname{Cot}(\alpha / 2)-r \cdot \operatorname{Cot}(\beta / 2)) \cdot \operatorname{Sin}(\beta)
$$

maka nilai $n$ dapat dituliskan kembali sebagai:

$$
i=\left[\frac{\left(c-r \cdot \operatorname{Cot}\left(\frac{\alpha}{2}\right)-r \cdot \operatorname{Cot}\left(\frac{\beta}{2}\right)\right) \cdot \operatorname{Sin}(\beta)}{(2 \cdot r-\rho)}\right]
$$

Sehingga total panjang bagian mendatar $(T P B D)$ adalah sebagai berikut:

$$
T P B D=\sum_{i=1}^{i}\left[a-r .\left(\operatorname{Cot}\left(\frac{\beta}{2}\right)+\operatorname{Cot}\left(\frac{\gamma}{2}\right)\right)-(2 \cdot r-\rho) \cdot(i-1)(\operatorname{Cot}(\beta)+\operatorname{Cot}(\gamma))\right] \ldots \text { (1) }
$$

Dimana, $\rho$ adalah lebar overlap antar dua lintasan pahat. Strategi direction parallel ini memungkinkan $\rho$ sama dengan nol (0).

Penghematan bagian mendatar:

Lintasan penghematan bagian mendatar merupakan pengurangan panjang lintasan mendatar CE menjadi CD.

$$
\begin{aligned}
& \overline{D E}=\frac{\overline{A D} \cdot \sin (1 / 4 \beta)}{\sin \left(180^{\circ}-\beta\right)} . \\
& \overline{G H}=\frac{\overline{C G} \cdot \sin (1 / 4 \gamma)}{\sin \left(180^{\circ}-\gamma\right)} .
\end{aligned}
$$

$n=i-1$

Persamaan (2.a) digunakan pada $n$ ganjil sedangkan (2.b) digunakan pada $n$ genap.

Panjang bagian menaik:

Total panjang bagian menaik (TPBN) diestimasi sebagaipenjumlahan dari AI+BI, $T P B N=A I+B I$, dapat dihitung sebagai berikut:

$\overline{A I}=c-r \cdot \operatorname{Cot}\left(\frac{\alpha}{2}\right)-r \cdot \operatorname{Cot}\left(\frac{\beta}{2}\right)$

$$
\overline{B I}=b-r \cdot \operatorname{Cot}\left(\frac{\alpha}{2}\right)-r \cdot \operatorname{Cot}\left(\frac{\gamma}{2}\right)
$$

$$
T P B N=\left(c-r \cdot \operatorname{Cot}\left(\frac{\alpha}{2}\right)-r \cdot \operatorname{Cot}\left(\frac{\beta}{2}\right)+b-r \cdot \operatorname{Cot}\left(\frac{\alpha}{2}\right)-r \cdot \operatorname{Cot}\left(\frac{\beta}{2}\right)\right)
$$

Panjang bagian untuk menghilangkan scallop 
Pada strategi direction parallehasil pngembangan, bagian untuk menghilangkan scallop adalah dengan menambah lintasan pahat sepanjang batas bentuk rongga (AI dan BI). Jalur pembuangan scallop pada strategi hasil pengembangan diperlihatkan di Gambar 1.

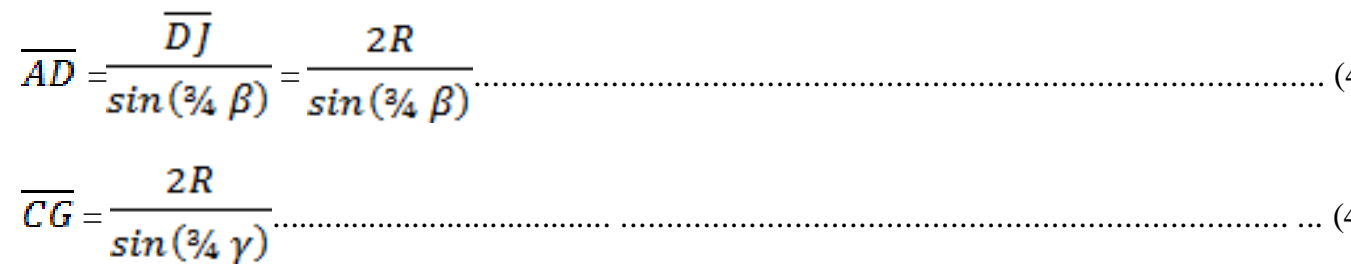

Persamaan (4.a) digunakan pada $n$ ganjil sedangkan (4.b) digunakan pada $n$ genap.

Panjang lintasan pahat untuk pemesinan pocket segitiga menggunakan strategi contour parallel dapat dituliskan sebagai fungsi $f(a, b, y, a, b, c, r)$ yang merupakan penjumlahan dari persamaan (1), persamaan (3) dan persamaan (4a atau 4b) dikurangi persamaan (2a atau 2b).

\section{Pengembangan Strategi Berbasis Strategi Contour Parallel}

Pengembangan strategi dilakukan dengan membangkitkan lintasan pahat tanpa menggunakan overlappingdan menambahkan lintasan pahat untuk memotong daerah dimana masih terdapat scallop. Pahat yang dipakai berdiameter $2 r$. Langkah-langkah pembangkitan lintasan pahat diawali dengan melakukan offset ke dalam sejauh diameter pahat $(r)$. Hasil offset itu adalah segitiga ABC.

Langkah selanjutnya adalah melakukan offset ke dalam terhadap segitiga ABC sejauh $2(r-\rho)$. Demikian seterusnya hingga mencapai lintasan ke $n$. Namun hal yang perlu diperhatikan dalam pengembangan strategi ini adalah $\rho$ bernilai nol (0), karena pengembangan strategi ini tidak memerlukan overlapping. Pemesinan pocket segitiga dengan menggunakan strategi contour parallel tanpa menggunakan overlapping dapat dilihat pada Gambar 2.

Dari Gambar 2 terlihat bahwa lintasan pahat terdiri dari tiga bagian yaitu:

- $\quad$ Bagian yang mengelilingi (sejajar) boundary pocket (ABC dan DEF)

- Bagian yang menaik yang menghubungkan lintasan pahat yang sejajar dengan $\mathrm{AB}$

- Bagian penghilang scallop. Gambar bagian penghilang scallop dapat dilihat pada Gambar 3

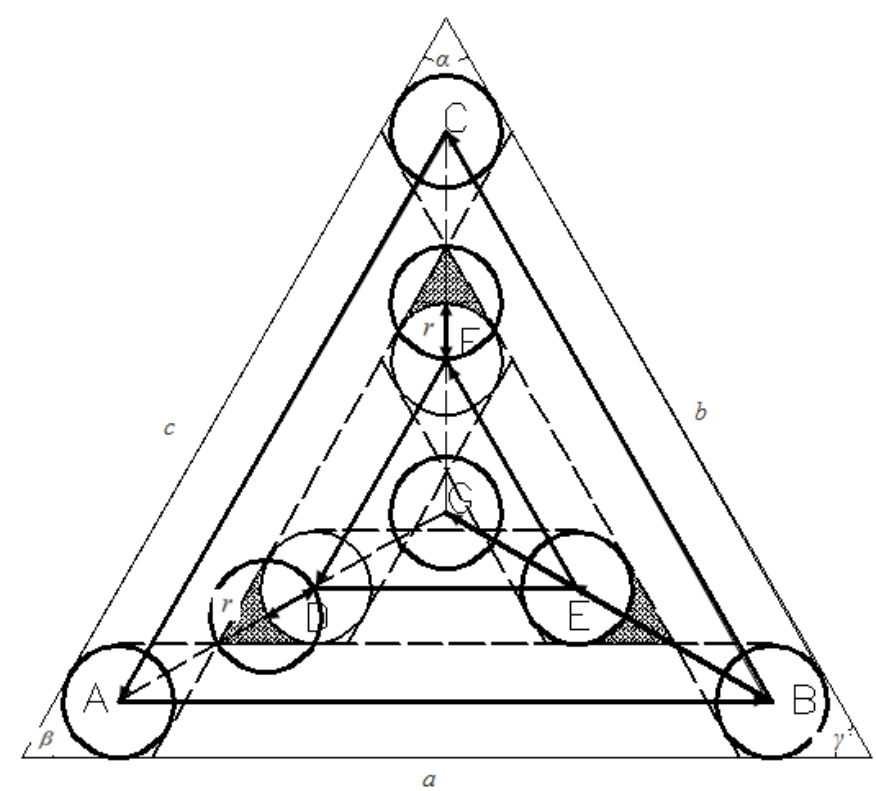

Gambar 2. Lintasan pahat pengembangan strategi contour parallel 


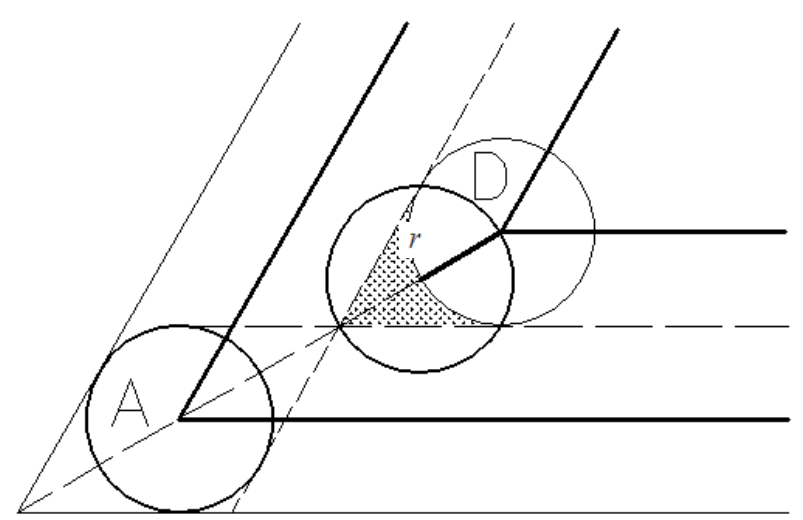

Gambar 3 Gambar lintasan penghilang scallop sejauh $r$

Panjang bagian yang sejajar keliling rongga:

Garis offset yang paling dekat dengan batas rongga (lintasan pahat terluar) berjarak sebesar radius $(r)$ pahat dari garis kontur rongga sehingga untuk segitiga ABC:

$$
\overline{A B}+\overline{B C}+\overline{C A}=(a+b+c)-2 \cdot r \cdot(\operatorname{Cot}(\alpha / 2)+\operatorname{Cot}(\beta / 2)+\operatorname{Cot}(\gamma / 2))
$$

Untuk mencari jumlah segitiga yang sejajar dengan batasrongga, perlu dicari terlebih dahulu besarnya $h$ (lihat Gambar 4).

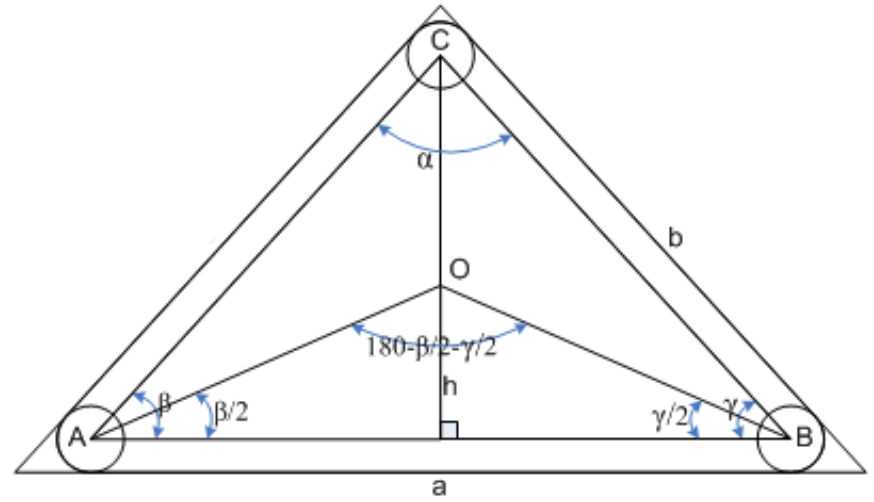

Gambar 4 Nilai $h$ untuk mencari jumlah segitiga yang sejajar dengan batas rongga

Dari Gambar 4, dengan hukum sinus dapat dicari nilai $h$ sebagai berikut:

$$
\begin{aligned}
& \frac{\overline{A B}}{\operatorname{Sin}(180-\beta / 2-\gamma / 2)}=\frac{\overline{O A}}{\operatorname{Sin}(\gamma / 2)}=\frac{\overline{O B}}{\operatorname{Sin}(\beta / 2)} \\
& \overline{O A}=\frac{\overline{A B} \cdot \operatorname{Sin}(\gamma / 2)}{\operatorname{Sin}(180-\beta / 2-\gamma / 2)} \operatorname{dan} \overline{O B}=\frac{\overline{A B} \cdot \operatorname{Sin}(\beta / 2)}{\operatorname{Sin}(180-\beta / 2-\gamma / 2)}
\end{aligned}
$$

Sehingga, 


$$
\begin{aligned}
& h=\overline{O A} \cdot \operatorname{Sin}(\beta / 2)=\overline{O B} \cdot \operatorname{Sin}(\gamma / 2)=\frac{\overline{A B} \cdot \operatorname{Sin}(\beta / 2) \cdot \operatorname{Sin}(\gamma / 2)}{\operatorname{Sin}(180-\beta / 2-\gamma / 2)}=\frac{\overline{A B} \cdot \operatorname{Sin}(\beta / 2) \cdot \operatorname{Sin}(\gamma / 2)}{\operatorname{Sin}(180-(90-\alpha / 2))} \\
& h=\frac{\overline{A B} \cdot \operatorname{Sin}(\beta / 2) \cdot \operatorname{Sin}(\gamma / 2)}{\operatorname{Cos}(\alpha / 2)}=\frac{(a-r \cdot(\operatorname{Cot}(\beta / 2)+\operatorname{Cot}(\gamma / 2))) \cdot \operatorname{Sin}(\beta / 2) \cdot \operatorname{Sin}(\gamma / 2)}{\operatorname{Cos}(\alpha / 2)}
\end{aligned}
$$

Selanjutnya jumlah segitiga dalam yang sejajar batas rongga adalah:

$$
n=\frac{h}{2 \cdot r-\rho}=\frac{(a-r \cdot(\operatorname{Cot}(\beta / 2)+\operatorname{Cot}(\gamma / 2))) \cdot \operatorname{Sin}(\beta / 2) \cdot \operatorname{Sin}(\gamma / 2)}{(2 \cdot r-\rho) \cdot \operatorname{Cos}(\alpha / 2)}
$$

Dimana nilai $n$ merupakan pembulatan keatas.

Total panjang lintasan pahat yang sejajar batas rongga:

$$
\sum_{i=1}^{n}(a+b+c)-((2 \cdot r)+2 \cdot(2 \cdot r-\rho) \cdot(i-1)) \cdot(\operatorname{Cot}(\alpha / 2)+\operatorname{Cot}(\beta / 2)+\operatorname{Cot}(\gamma / 2))
$$

Total panjang lintasan untuk menghilangkan scallop:

$$
(n-1) \times 2 \times 2((r / \operatorname{Sin} 1 / 2\{\operatorname{Max} \beta, \gamma\})-r)
$$

Panjang lintasan menaik :

Panjang lintasan menaik dapat dilihat pada segitiga BEI Gambar 5.

Total panjanglintasanmenaikadalah:

$$
(n-1)(2 r / \operatorname{Sin} 1 / 2\{\operatorname{Min} \beta, \gamma\})
$$

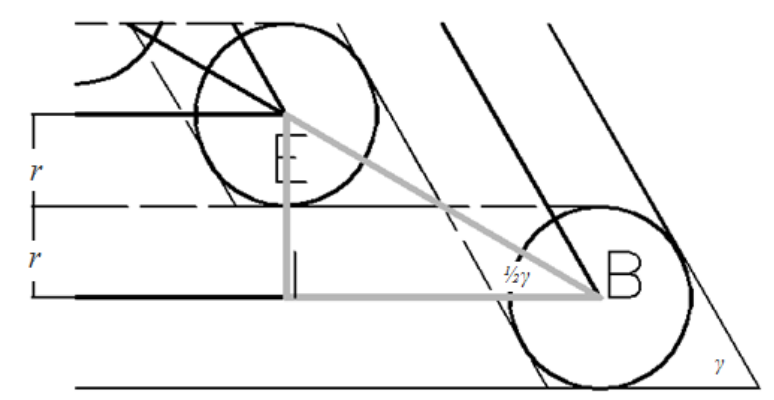

Gambar 5 Lintasan menaik pengembangan strategi contour parallel

Panjang lintasan pengembangan strategi contour parallel untuk pemesinan ronggasegitiga dapat dituliskan sebagai fungsi $f(a, b, Y, a, b, c, \rho, r)$ yang merupakan penjumlahan dari persamaan (5), persamaan (6), dan persamaan (7).

\section{HASIL DAN PEMBAHASAN}


Contoh Numerik 1

Hasil perhitungan pada sebuah pocket segitiga sama sisi yang memiliki sudut $(\alpha=B=y$ $\left.=60^{\circ}\right)$ dengan panjang sisi $(a, b, c)=10 \mathrm{~cm}$ dan jari-jari kelengkungan sudut dan radius pahat $10 \mathrm{~mm}$. [1] Panjang lintasan pahat strategi direction parallel adalah388,231 $\mathrm{mm}$ dan strategi contour parallel adalah $251,28 \mathrm{~mm}$. Pengembangan startegi direction parallel menghasilkan panjang lintasan pahat yang lebih pendek, yaitu sebesar $297,175 \mathrm{~mm}$. Namun pengembangan strategi contour parallel tanpa overlapping memberikan lintasan pahat yang lebih panjang, yaitu sebesar $276,08 \mathrm{~mm}$.

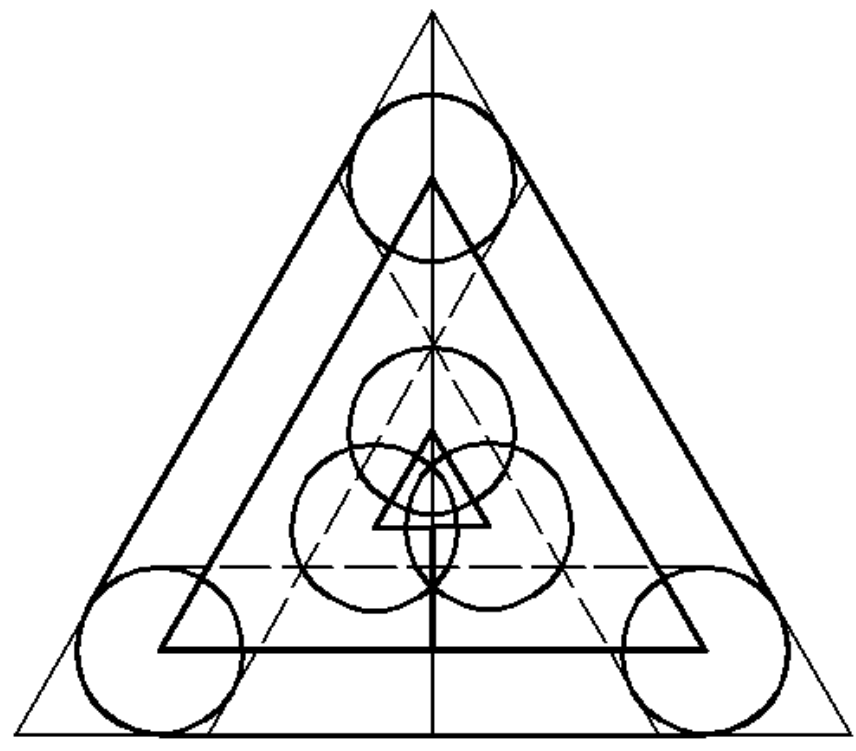

Gambar 6 Strategi pemesinan contour parallel dengan overlapping

Berdasarkan hasil perhitungan pada contoh numerik 1 menunjukkan bahwa strategi pemesinan contour parallel dengan overlapping memberikan lintasan pahat yang paling pendek. Hal ini disebabkan oleh besarnya sudut batas rongga segitiga sama sehingga penentuan besarnya overlapping ( $\rho$ ) juga sama. Scallop atau daerah sisa hasil pemotongan diselesaikan oleh lintasan pahat ke $(n+1)$.

Contoh numerik 2

Pocket segitiga memiliki sudut $\alpha=90^{\circ}, B=53^{\circ}, y=37^{\circ}$ dengan panjang sisi a $=100$ $\mathrm{mm}, \mathrm{b}=80 \mathrm{~mm}, \mathrm{c}=60 \mathrm{~mm}$. Hitung panjang lintasan pahat jika jari-jari kelengkuangan sudut dan radius pahat $=5 \mathrm{~mm}$. [1] strategi direction parallel menghasilkan panjang lintasan pahat $=407,846 \mathrm{~mm}$ dan strategi contour parallel dengan overlapping menghasilkan panjang lintasan pahat $=316,0176 \mathrm{~mm}$. Hasil pengembangan strategi direction parallel mampu memberikan panjang lintasan yang lebih pendek yaitu sebesar $318,347 \mathrm{~mm}$ dan pengembangan strategi contour parallel tanpa overlapping juga mampu memberikan panjang lintasan pahat yang lebih pendek sebesar $296,578 \mathrm{~mm}$.

Berdasarkan hasil perhitungan pada sebuah segitiga yang memiliki sudut-sudut yang tidak sama pada ketiga sisinya. Pengembangan strategi direction parallel mampu menghasilkan lintasan pahat yang lebih pendek daripada strategi contour parallel dengan overlapping. Hal ini disebabkan oleh besarnya overlapping ditentukan oleh sisi yang memiliki scallop terpanjang sedangkan setiap sisi memiliki panjang scallop yang tidak sama sehingga terdapat lintasan yang mengalami pemesinan berulang yang terlalu panjang. 


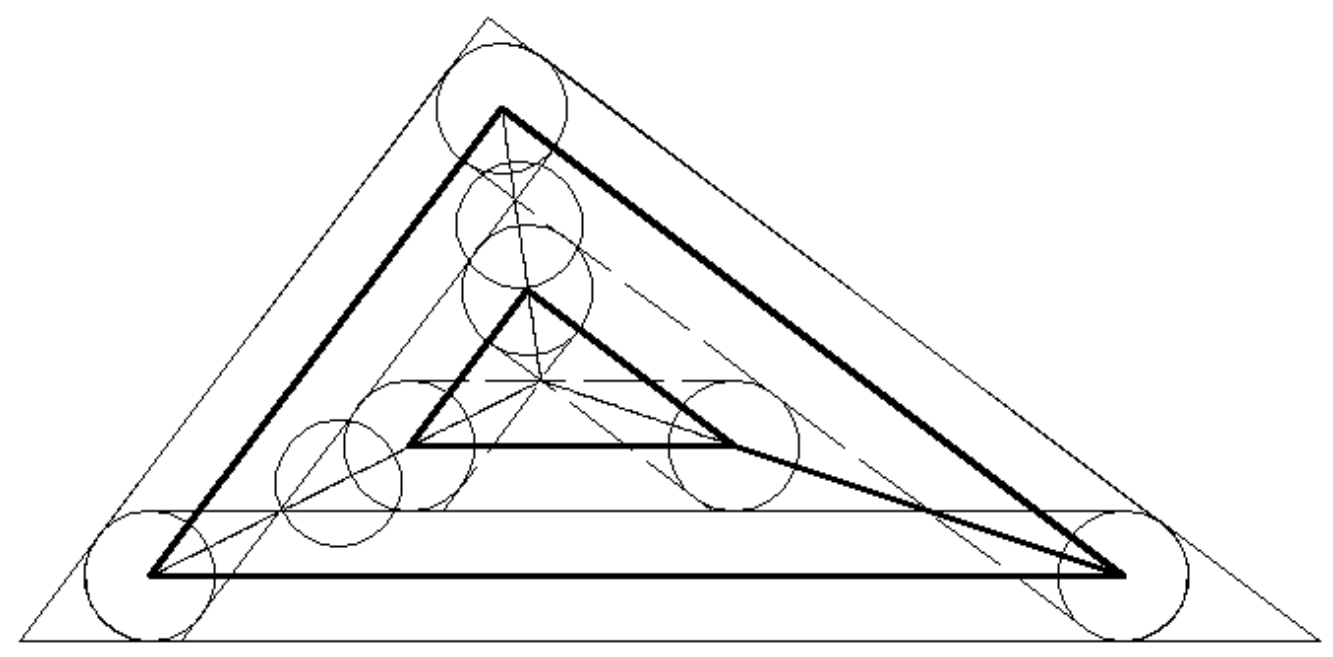

Gambar 7 Strategi pemesinan contour parallel tanpa overlapping

Strategi direction parallel yang dikembangkan bukanlah strategi pemesinan yang paling cepat padacontoh kasus ini. Strategi pemesinan yang paling cepat adalahstrategi pemesinan contour parallel tanpa overlapping. Strategi ini memiliki lintasan pahat yang paling pendek karena lintasan menaik yang digunakan merupakan lintasan miring terpanjang yang dibentuk oleh sudut terkecil. Sementara lintasan untuk menghilangkan sisa pemotongan adalah lintasan pada batas pocket yang memilikisudut lebih besar.

\section{KESIMPULAN}

Berdasarkan hasil perhitungan pada contoh numerik 1 dan contoh numerik 2 diketahui bahwa strategi pemesinan contour parallel mampu memberikan lintasan pahat yang paling pendek. Strategi contour parallel dengan overlapping cocok untuk segitiga sama sisi $(\alpha=B=y$ $=60^{\circ}$ ), sedangkan strategi contour parallel tanpa overlapping cocok untuk segitiga yang memiliki sudut berlainan $(\alpha \neq B \neq \mathrm{Y})$. Pemilihan strategi untuk pemesinan bentuk rongga segitiga harus mempertimbangkan ukuran pahat dan bentuk segitiga untuk memperoleh lintasan pahat yang paling pendek.

\section{DAFTAR PUSTAKA}

[1] Arya, S., Cheng, S.W., Mount, D.M., 2001, Approximation Algorithms for Multiple-Tool Milling,Int'l. J. of Computational Geometry and Applications, 11, 339-372.

[2] Chaeron, M., 2006, Model Analitis Panjang Lintasan Pahat untuk Pemesianan Bentuk Rongga (Pocket) Segitiga, Jurnal Teknologi Industri, Vol. X, No. 3, juli 2006.

[3] Kramer, T.R., 1992, Pocket Milling with Tool Engagement Detection, Journal of Manufacturing System, Vol. 11, No. 2, pp. 114-123.

[4] Kyoung, Y.M., Cho, K.K., Jun, C.S., 1997, Optimal Tool Selection for Machining in Process Planning, Computers Industrial Engineering, Vol. 33, No. 3-4, pp. 505-508

[5] Purcell, Edwin J., Varberg, D., 1996, Kalkulus dan Geometry Analitis, Edisi Keempat, Erlangga, Jakarta.

[6] Veeramani, D., Gau, Y.S., 1997, Selection of an Optimal Set of Cutting-Tool for Triangular Pocket, International Journal of Production Research, Vol.35, No. 9, pp. 2621-2637. 